\title{
SOME FACTORS AFFECTING THE STRENGTH OF THE CEMENT-METAL INTERFACE
}

\author{
MARTIN H. STONE, ROSEMARY WILKINSON, IAN G. STOTHER
}

From Glasgow Royal Infirmary and the University of Strathclyde

\begin{abstract}
A manufacturing technique to increase the bonding between bone cement and metal prostheses has been assessed in the laboratory by "push-out" tests, and the effects of contamination of the cement and of the prosthesis with blood and intramedullary contents have been studied. The technique, known as pre-coating, increases bond strength; this increase is preserved after contamination of the cement which does, however, cause some lowering of interface shear strength. The implications for clinical practice are discussed.
\end{abstract}

Loosening is one of the major causes of late failure of joint prostheses. It occurs at either the cement-bone or cement-prosthesis interface (Fig. 1). Even when an implant is apparently firm in the cement mantle at post mortem or revision, a fibrous layer some $100 \mu \mathrm{m}$ thick has been found in some cases separating cement and femoral stem (Fornasier and Cameron 1976). This layer is sufficient to allow micromovement to occur, though the relevance of this to the durability of the prosthesis is not clear.

Cement debris has been found adjacent to loose prostheses (Willert and Semlitsch 1975), but its precise origin is unknown. However, many of the particles are so fine that it seems unlikely that they are all produced at operation. Micromovement before fibrous ingrowth can occur may be the source of some of the debris.

The importance of cement particles lies in their biocompatibility. Although bone cement is well tolerated in bulk, it is known that particles may activate macrophages and be associated with bone resorption (Maguire et al. 1987). Obvious ways of reducing relative micromovement and the amount of debris, are to increase the strength of the cement-prosthesis interface or to use cementless fixation. Our study attempts to assess one of the techniques currently available to increase interface strength, namely that of pre-coating

M. H. Stone, MPhil, FRCS, Senior Orthopaedic Registrar Southampton General Hospital, Tremona Road, Southampton SO9 $4 X Y$, England

I. G. Stother, MA, FRCS, Consultant Orthopaedic Surgeon Glasgow Royal Infirmary, 104 Castle Street, Glasgow G4 OSF, Scotland.

R. Wilkinson, BA, PhD, Lecturer

Bioengineering Unit. University of Strathclyde, 106 Rottenrow, Glasgow G4 ONW, Scotland.

Correspondence should be sent to $\mathrm{Mr} \mathrm{M}$. H. Stone.

(C) 1989 British Editorial Society of Bone and Joint Surgery

$0301-620 \times / 89 / 2035 \$ 2.00$

J Bone Joint Surg [Br] 1989;71-B:217-21. the prosthesis. Pre-coating is a manufacturing technique by which a fine layer of polymethyl methacrylate (PMMA), less than $0.1 \mathrm{~mm}$ thick, is applied to the surface of the prosthesis in such a way as to maximise the strength of the interface. The pre-coated prosthesis is then inserted in the normal way.

\section{MATERIALS AND METHODS}

Laboratory tests were made on rods of cobalt-chrome and titanium 318 alloys, $5 \mathrm{~cm}$ in length and $6.4 \mathrm{~mm}$ in diameter, to evaluate the interface shear strength (ISS) between cement and rod. Control studies used sterile CMW 1 cement, Palacos $R$ (with gentamicin) cement and clean alloy rods both shot-blasted and pre-coated. Cement obtained at operations for hip and knee arthroplasty, as described below, was used to assess the effect of the organic materials such as blood or fat which

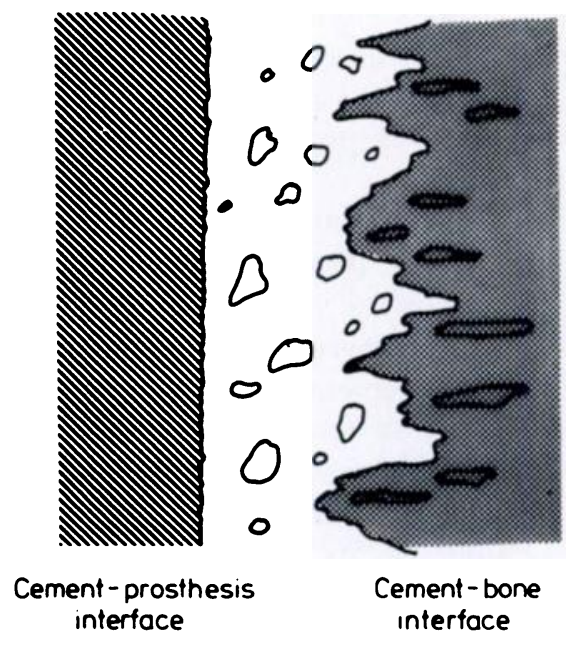

Fig. 1

Diagram of the interfaces between a cemented prosthesis and bone. 
become incorporated during surgery. This cement is termed contaminated cement.

During total hip replacement a bolus of cement is inserted into the prepared femoral shaft, and when the prosthesis is inserted some cement extrudes. Some of this was collected and used immediately to prepare "femoral cement" specimens. Similar cement from the acetabulum and from either side of a surface replacement arthroplasty of the knee was used, and labelled "acetabular cement" and "knee cement" respectively. Knee cement differs from hip cement in that replacement is normally carried out under a tourniquet, so there is little bleeding but, since the intra-medullary cavity is not reamed, fat exudes from the bone.

We studied six test groups, each with both standard shot-blasted and pre-coated finishes in titanium and cobalt-chrome alloy: 1. control CMW 1;2. control Palacos R; 3. femoral cement; 4. acetabular cement; 5. knee cement; 6 . clean Palacos $\mathrm{R}$, but with rods which had been contaminated at hip arthroplasty.

Test rods were placed in teflon moulds and, two to four minutes after mixing, approximately $3 \mathrm{ml}$ of cement was added to each mould (Fig. 2). A plunger was then inserted over the rod and pressed home firmly. A $1 \mathrm{lb}$ $(0.45 \mathrm{~kg})$ weight was placed on the plunger while the cement set. After 15 minutes the moulds were dismantled and the specimens removed then stored at room temperature for between four and 17 days before testing.

Specimens under test were placed in an aluminium cup which fitted a machined plate bolted to the moving cross-head of an Instron mechanical test machine. A ball-bearing was placed between the top of the rod and the loading bar to reduce bending moments. The crosshead was raised until the ball-bearing just contacted the loading bar, then the cross-head was set to drive upwards at $0.5 \mathrm{~mm} / \mathrm{min}$. The maximum load at failure was converted to an interface shear stress (ISS), representing the interface shear strength, using the formula ISS = $\mathbf{P} / \mathbf{A}$, where $\mathbf{P}=$ maximum load and $\mathbf{A}=$ interface area. At least 10 specimens were tested in each group.

\section{RESULTS}

In the uncoated specimens, the cement and alloy separated cleanly at their interface and the cement remained intact. In the pre-coated specimens, failure was at the interface between the pre-coating and the new cement. Again the cement mantle remained intact.

A typical Instron recording is shown in Figure 3. There is a gradual increase in load until the specimen is fully seated in the cup, then the slope rises steeply to a maximum. Failure at this point was often accompanied by an audible crack with a dramatic reduction of load to a near constant level. This continued load was required to overcome friction between the cement mantle and the rod or pre-coat; it remained much the same if the specimen was removed and re-inserted upside down.
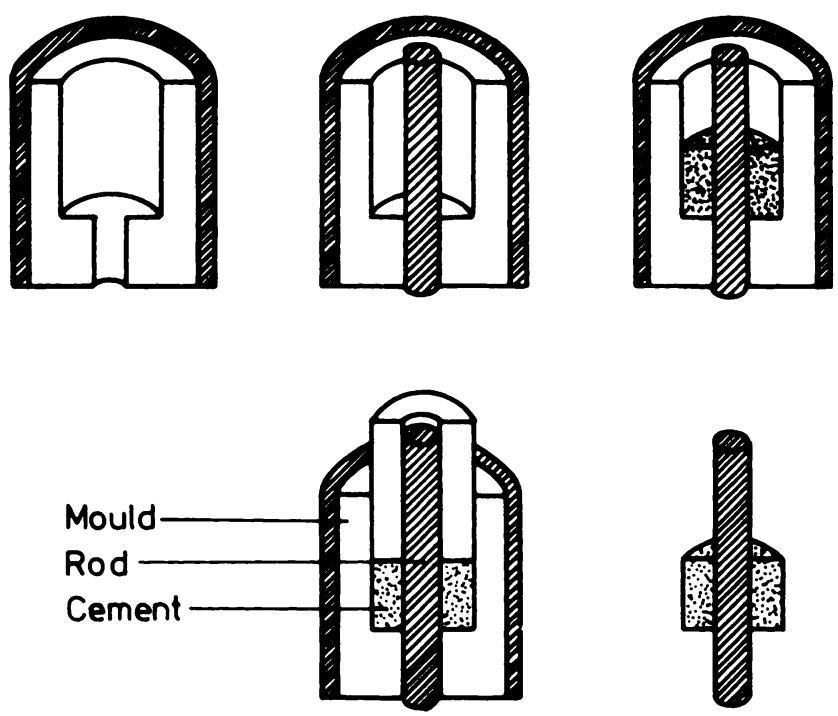

Fig. 2

Diagram to show the preparation of the specimens.

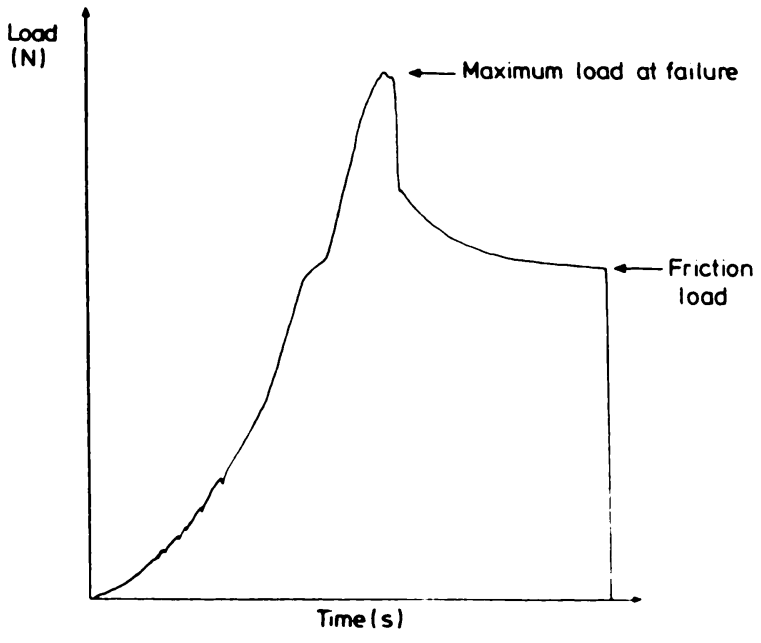

Fig. 3

An Instron recording of a typical test.

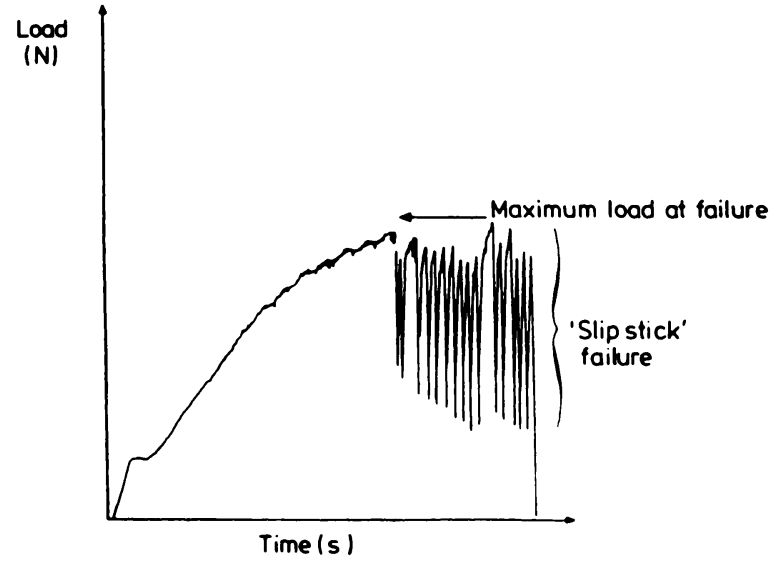

Fig. 4

Recording showing "slip-stick" behaviour. 


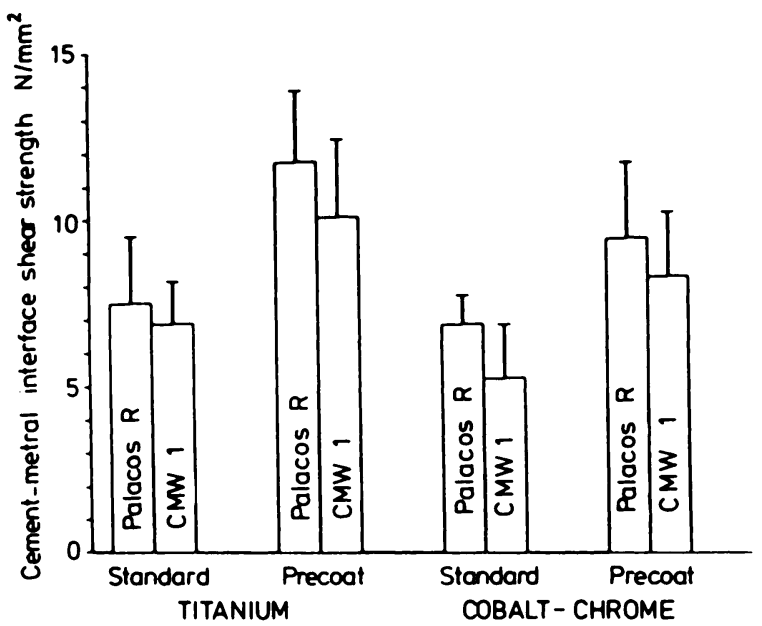

Fig. 5

Comparison between control Palacos R and control CMW 1.

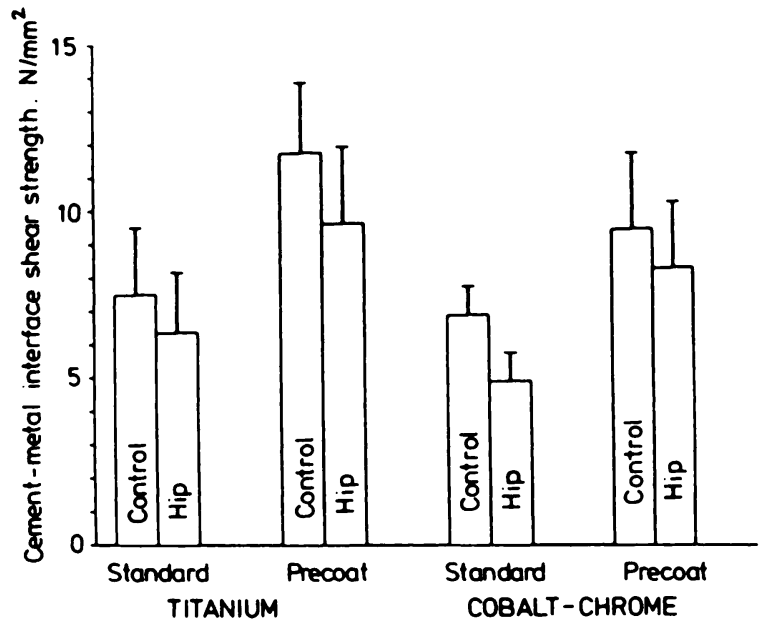

Fig. 6

Comparison between control Palacos $\mathbf{R}$ and cement contaminated at hip arthroplasty.

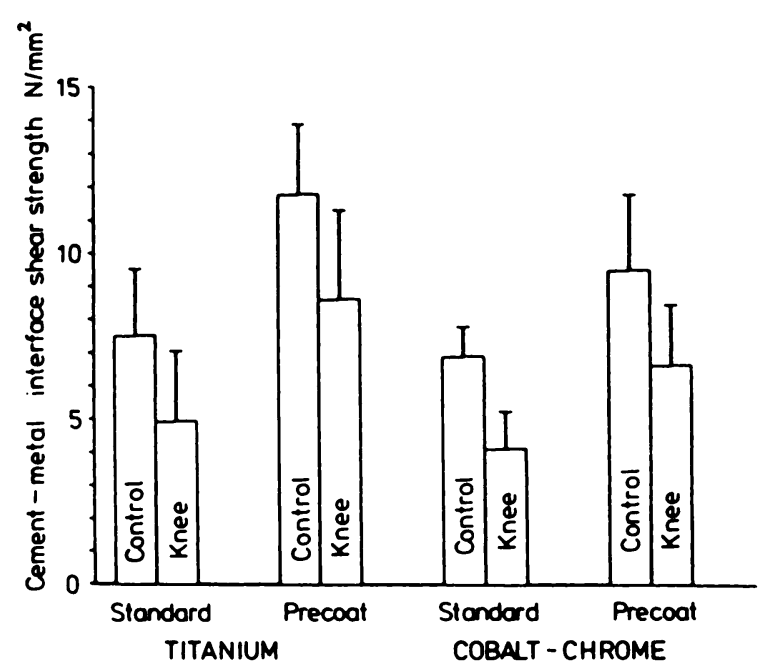

Fig. 7

Comparison between control Palacos $\mathbf{R}$ and cement contaminated at knee arthroplasty.
The loading graphs for the contaminated pre-coated specimens were somewhat different. An example is shown in Figure 4. There appears to be a "slip-stick-slip" failure. This may represent a different mode of failure; the contamination appeared to act as a lubricant between the cement and the rod.

Controls. The interface shear strengths for all the groups are given in Table I. Figure 5 compares the results for the two control groups. Absolute differences between the cement types are small and only in the cobalt-chrome specimens was there any significant difference $(p<0.01)$. Pre-coating increased the ISS significantly $(\mathrm{p}<0.01)$ for all groups. With CMW cement, titanium interfaces were stronger than cobalt-chrome $(p<0.01)$ but this was an isolated observation.

Hip cement. There was no significant difference between femoral and acetabular cement specimens and so these were added to form a "hip cement" group. The results for hip cement with Palacos $R$ are compared in Figure 6. Hip cement used with pre-coated titanium and shotblasted cobalt-chrome provided a significantly weaker bond than the control values ( $p<0.01)$, but the other two materials were similar. Pre-coating produced stronger interfaces $(p<0.001)$ and, again, the titanium interfaces were stronger $(\mathrm{p}<0.01)$.

Knee cement. The results of using knee cement and Palacos $\mathbf{R}$ control values are compared in Figure 7. All knee cement specimens were weaker than the controls $(p<0.01)$. Pre-coated specimens were stronger than the shot-blasted ones $(p<0.01)$ but there was no significant difference between titanium and cobalt-chrome.

Contaminated alloy. The results using rods which had been exposed to body fluids at a hip arthroplasty are compared with control Palacos values in Figure 8. There is a massive loss in ISS $(p<0.001)$, but the interfaces are

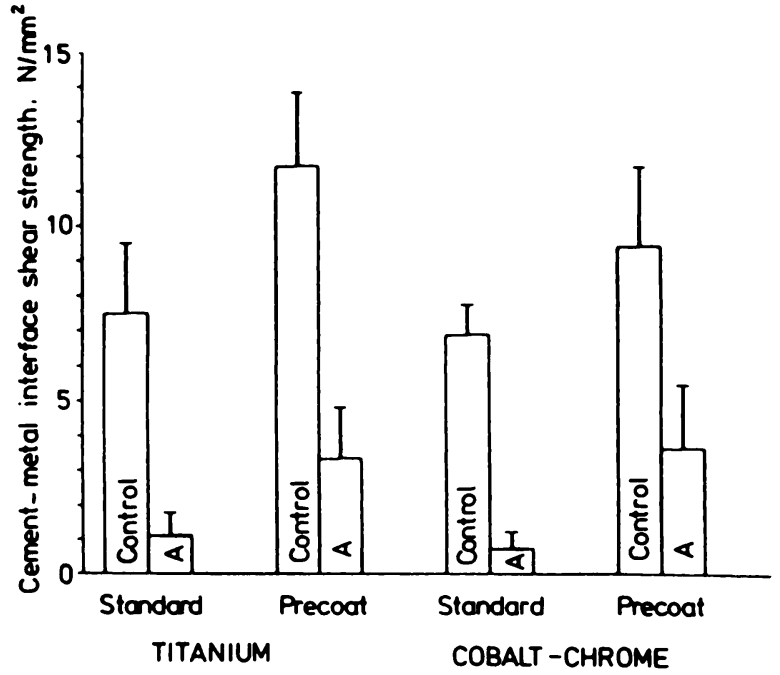

Fig. 8

Comparison between control Palacos $\mathbf{R}$ and specimens prepared with contaminated metal. 
stronger after pre-coating $(p<0.001)$. There was no significant difference between titanium and cobaltchrome.

\section{DISCUSSION}

It seems likely that cement will continue to be a useful material in joint replacement. Even if the late results of cementless fixation live up to the expectations of its proponents, patients with poor bone stock and those who cannot tolerate a long rehabilitation, will still require bone cement. The best technique and design for cemented prostheses will therefore continue to matter.

Our work indicates that pre-coating produces a stronger interface. The maximum interface shear strength in clinical practice between surgical alloy and standard viscosity bone cement is about $12 \mathrm{~N} / \mathrm{mm}^{2}$ for pre-coated stems and $8 \mathrm{~N} / \mathrm{mm}^{2}$ for shot-blasted stems. McNeice and Amstutz (1975) calculated that ISS values of $18 \mathrm{~N} / \mathrm{mm}^{2}$ are required in clinical practice, but the effective strength of an interface depends not only on the shear strength but also on the stem design. Changes in the geometry of the interface, particularly the presence of macroscopic indentations or surface roughness have large effects on the load which can be applied before failure.

The use of macroscopic interlock between materials of such different moduli of elasticity as cement and metal requires very careful design. There is a danger of introducing local high stresses into the cement; these could result in fatigue failure, loss of fixation and the problem of abrasive wear. Such processes as deep shot peening will increase interface strength, but breakdown of the interface between a rough surface and cement may cause abrasion at the whole interface and produce a large amount of debris. Materials are often less compatible in particulate form; cement debris may contribute even more loosening. Cement particles may also cause wear on metal (I. A. Brown, personal communication), especially when they may act as a grinding material. Thus any increase in interface strength must be balanced against the risks of failure.

An alternative approach is to accept movement at the cement-prosthesis interface and then to try to minimise the consequences. This approach to femoral stem design in hip replacement has been applied in the Exeter prosthesis, in which a polished surface minimises abrasive wear, and the geometry allows re-stabilisation after some distal migration in the cement mantle (Bradley et al. 1987). The long-term clinical results from Exeter (Bradley et al. 1987), compare well with most other published results (Charnley and Cupic 1973; Harris, McCarthy and O’Neill 1982; Stauffer 1982; Sutherland et al. 1982; Johnston and Crowninshield 1983; Wroblewski 1986).

The results of hip replacement depends on many factors; an important one which cannot be controlled by the surgeon is the bone stock. If this is poor, the initial fixation of a cementless device is difficult and there may be problems with the absorption of hoop stresses in the cement caused by distal migration of collarless stems, such as the Exeter prosthesis, although this has not been clinically obvious.

The geometry of the stem must be consistent with the mode of fixation which is chosen. Distal migration and re-stabilisation can only occur if the stem is straight, uniformly tapered, collarless and without projections or indentations (Bradley et al. 1988). Stem designs with collars or flanges, "teardrops" or other macroscopic changes of section cannot re-stabilise in the same way. Laboratory studies indicate that cement stresses will be

Table I. Interface shear strengths (see text)

\begin{tabular}{|c|c|c|c|c|c|}
\hline Cement & & Ti318 & $\begin{array}{l}\text { Conted } \\
\text { Ti318 }\end{array}$ & HS21 & $\begin{array}{l}\text { Coated } \\
\text { HS21 }\end{array}$ \\
\hline $\begin{array}{l}\text { Control } \\
\text { CMW } 1\end{array}$ & $\begin{array}{l}\text { mean } \\
\text { s.d. } \\
\text { number }\end{array}$ & $\begin{array}{l}6.90 \\
1.30 \\
11\end{array}$ & $\begin{array}{l}10.10 \\
2.37 \\
13\end{array}$ & $\begin{array}{l}5.26 \\
1.63 \\
12\end{array}$ & $\begin{array}{l}8.33 \\
1.93 \\
10\end{array}$ \\
\hline $\begin{array}{l}\text { Control } \\
\text { Palacos R }\end{array}$ & $\begin{array}{l}\text { mean } \\
\text { s.d. } \\
\text { number }\end{array}$ & $\begin{array}{l}7.50 \\
2.03 \\
10\end{array}$ & $\begin{array}{l}11.77 \\
2.12 \\
12\end{array}$ & $\begin{array}{l}6.89 \\
0.88 \\
10\end{array}$ & $\begin{array}{l}9.50 \\
2.26 \\
10\end{array}$ \\
\hline $\begin{array}{l}\text { Acetabular } \\
\text { cement }\end{array}$ & $\begin{array}{l}\text { mean } \\
\text { s.d. } \\
\text { number }\end{array}$ & $\begin{array}{l}6.79 \\
1.67 \\
12\end{array}$ & $\begin{array}{l}10.37 \\
2.38 \\
13\end{array}$ & $\begin{array}{l}5.12 \\
0.66 \\
11\end{array}$ & $\begin{array}{l}8.77 \\
1.85 \\
19\end{array}$ \\
\hline $\begin{array}{l}\text { Proximal } \\
\text { femoral cement }\end{array}$ & $\begin{array}{l}\text { mean } \\
\text { s.d. } \\
\text { number }\end{array}$ & $\begin{array}{l}5.91 \\
1.95 \\
11\end{array}$ & $\begin{array}{l}8.85 \\
2.08 \\
12\end{array}$ & $\begin{array}{l}4.69 \\
1.03 \\
11\end{array}$ & $\begin{array}{l}7.43 \\
2.04 \\
10\end{array}$ \\
\hline $\begin{array}{l}\text { Hip joint } \\
\text { cement (total) }\end{array}$ & $\begin{array}{l}\text { mean } \\
\text { s.d. } \\
\text { number }\end{array}$ & $\begin{array}{l}6.37 \\
1.82 \\
23\end{array}$ & $\begin{array}{l}9.64 \\
2.33 \\
25\end{array}$ & $\begin{array}{l}4.90 \\
0.87 \\
22\end{array}$ & $\begin{array}{l}8.31 \\
1.99 \\
29\end{array}$ \\
\hline $\begin{array}{l}\text { Knee joint } \\
\text { cement }\end{array}$ & $\begin{array}{l}\text { mean } \\
\text { s.d. } \\
\text { number }\end{array}$ & $\begin{array}{l}4.94 \\
2.13 \\
13\end{array}$ & $\begin{array}{l}8.58 \\
2.72 \\
11\end{array}$ & $\begin{array}{l}4.10 \\
1.13 \\
10\end{array}$ & $\begin{array}{l}6.59 \\
1.82 \\
13\end{array}$ \\
\hline $\begin{array}{l}\text { Clean Palacos } \mathbf{R} \\
\text { with contaminated } \\
\text { alloy }\end{array}$ & $\begin{array}{l}\text { mean } \\
\text { s.d. } \\
\text { number }\end{array}$ & $\begin{array}{l}1.12 \\
0.69 \\
11\end{array}$ & $\begin{array}{l}3.36 \\
1.47 \\
12\end{array}$ & $\begin{array}{l}0.74 \\
0.51 \\
11\end{array}$ & $\begin{array}{l}3.67 \\
1.84 \\
12\end{array}$ \\
\hline
\end{tabular}

reduced and stress transfer will be better if the prosthesis-cement interface remains tight (Ahmed, Raab and Miller 1984); techniques to increase interface strength are most applicable to stem designs which cannot re-stabilise.

This argument concerning the desirability of a strong cement-metal interface has been limited to the femoral component of a hip prosthesis, but it is generally accepted that failure at this interface will lead to clinical failure of other components of hip and knee replacements.

Conclusions. The inclusion of organic material at operation tends to weaken cement-metal interfaces. The fat exuding from the bone during knee replacement under tourniquet weakens the interface more than the 
blood which may contaminate cement during hip arthroplasty. Failure to remove the blood from a metal surface, for example, after a trial fitting of the component, will greatly reduce interface strength.

Pre-coating the metal produces stronger interfaces than those with shot-blasted finishes under all conditions. Biological contamination reduced the interface strength of the pre-coated specimens but they still gave a statistically significant increase in strength over the conventional finish. Pre-coating seems to confer an advantage to components in which increased interface strength would be beneficial. However, careful attention to the preparation of the bone bed and the surface of the implant also offers an increase in the strength of the cement-metal interface.

We would like to thank Zimmer UK for providing the test specimens, Kirby Warrick for cement, and the Greater Glasgow Research Support Group for financial support. Mr D. Smith and Mr C. Roper are to be thanked for technical assistance. Financial support for MHS was received from the Royal College of Surgeons of Edinburgh.

One or more of the authors have received or will receive benefits for personal and professional use from a commercial party related directly or indirectly to the subject of the article.

\section{REFERENCES}

Ahmed AM, Raab S, Miller JE. Metal/cement interface strength in cemented stem fixation. J Orthop Res 1984:2:105-18.

Bradley G, Fowler JL, Gie GA, et al. The long term results of cemented total hip arthroplasty: experience with a collarless femoral component. Clin Orthop in press.

Chamley J, Cupic $\mathbf{Z}$. The nine and ten year results of the low-friction arthroplasty of the hip. Clin Orthop 1973:95:9-25.

Fornasier VL, Cameron HU. The femoral stem/cement interface in total hip replacement. Clin Orthop 1976:116:248-52.

Harris WH, McCarthy JC Jr, O'Neill DA. Femoral component loosening using contemporary techniques of femoral cement fixation. J Bone Joint Surg [Am] 1982;64-A :1063-7.

Johnston RC, Crowninshield RD. Roentgenologic results of total hip arthroplasty: a 10-year follow-up study. Clin Orthop 1983:181: 92-8.

Maguire JK, Coscia MF, Lynch MH. Foreign body reaction to polymeric debris following total hip arthroplasty. Clin Orthop 1987:216:213-23
McNeice GM, Amstutz HC. Stress in protheses stem and supporting acrylic: a finite element study of hip replacement. Proceedings of Sth International Congress of Biomechanics. University of Jyraskyla 1975.

Staufier RN. Ten-year follow-up study of total hip replacement: with particular reference to roentgenographic loosening of the components. J Bone Joint Surg [Am] 1982;64-A :983-90.

Sutherland CJ, Wilde AH, Borden LS, Marks KE. A ten-year follow-up of one hundred consecutive Müller curved-stem total hipreplacement arthroplasties. J Bone Joint Surg [Am] $1982: 64-A: 970-82$

Willert HG, Semlitsch M. Reaction of the articular capsule to plastic and metallic wear products from joint endoprostheses. Sulzer Technical Retiew 1975:2:1-15.

Wroblewski BM. 15-21-year results of the Charnley low-friction arthroplasty. Clin Orthop 1986:211:30-5. 